\title{
La imagen del tiempo. El patrimonio como indicio histórico
}

\author{
María Florencia Bellingeri Visciarelli | Universidad Nacional de La Plata y Consejo Nacional de Investigaciones Científicas y \\ Técnicas, CONICET (Argentina)
}

URL de la contribución <www.iaph.es/revistaph/index.php/revistaph/article/view/3890>

"Es cierto que uno puede crear algo, que durará mil años, pero nadie puede decir quién estará vivo al cabo de un siglo" (CHI WU-FOU, 1634, citado por

NEEDHAM, 1970, en LYNCH, 1975: p. 109)

Si un indicio es tanto una manifestación que permite inferir la presencia de otra no perceptible y, a su vez, una cantidad pequeña de algo que no se revela de modo suficiente como para hacerla medible (REAL ACADEMIA ESPAÑOLA, 2017), se puede decir que los indicios son especies de pistas en el tiempo que nos permiten conjeturar acerca de hechos y procesos. Resulta entonces atinado describir el concepto de momento histórico -a propósito de la investigación en historia- como el presente aprehendido a su origen: un "luego" unido al "antes" (VIRNO, 2003). Sin embargo, un exceso de pasado puede generar una deformación y desintegración de la propia historia (NIETZCHE, 1977, citado en VIRNO, 2003).

Las prácticas de restauración de bienes de importancia patrimonial han situado en el debate las disyuntivas sobre cómo mirar el pasado y el futuro, y a partir de qué formas y procedimientos.

¿Qué hubiera sido, por ejemplo, de la apreciación del mural Ejercicio Plástico ideado por el artista mexicano David Alfaro Siqueiros en 1933 -junto a los argentinos Antonio Berni, Juan Carlos Castagnino, Lino Enea Spilimbergo y el uruguayo Enrique Lázaro-, si no se encontrara actualmente emplazado en el Museo Casa Rosada de la ciudad de Buenos Aires? Este objeto preciado nació como decoración de un sótano y fue fruto de la especulación económica primero, de la desidia luego $y$, finalmente, de la necesidad de rescatar, poner en valor y dar a conocer al público una obra de enorme importancia para el arte y la historia de Latinoamérica.
Ejercicio Plástico había sido especialmente ejecutado para el abovedado sótano de la fastuosa residencia de Natalio Botana -fundador en aquel entonces del Diario Crítica- en la quinta Los Granados, situada en Don Torcuato, zona de Gran Buenos Aires. A pesar de presentar una temática de carácter intimista, carente de contenido político por haber estado confeccionado en un ámbito privado; pretendía generar un aporte revolucionario desde la forma colectiva de su producción, la monumentalidad, la técnica mecánica con que se había realizado, la acción psicológica que generaba en el espectador y el realismo documental al que llegaba (SIQUEIROS; SPILIMBERGO; LÁZARO; CASTAGNINO; BERNI, 1933). Representaba también a la plástica moderna, por estar creado con materiales, herramientas y procedimientos acordes a la arquitectura de la época, los cuales jamás habían sido utilizados antes en Latinoamérica (SIQUEIROS; SPILIMBERGO; LÁZARO; CASTAGNINO; BERNI, 1933). Sin dejar de tener en cuenta que Ejercicio Plástico fue la única obra efectuada en territorio argentino por uno de los precursores del muralismo mexicano, como es David Alfaro Siqueiros -que por razones políticas no tenía en aquel período acceso a los muros públicos-, y que esta pieza representa el precedente para la formación del muralismo argentino, como se puede observar en la posterior constitución del Taller de Arte Mural en 1944.

En resumidas cuentas, luego de la muerte de Botana en 1941, la vivienda con el mural transita por distintos dueños que por desconocimiento y negligencia, descuidan la obra exponeniéndola a actos de vandalismo y filtraciones; generándole un deterioro material considerable. Fue en 1988 cuando Héctor Mendizábal, amante de los objetos antiguos, visita la quinta que para aquel entonces iba a ser rematada judicialmente. Toma conocimiento del mural, investiga acerca del mismo y rápidamente forma 


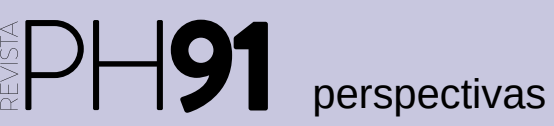

a debate Visiones patrimoniales para definir el objeto del siglo

| coordinan José Ramón Moreno Pérez, Marta García de Casasola Gómez

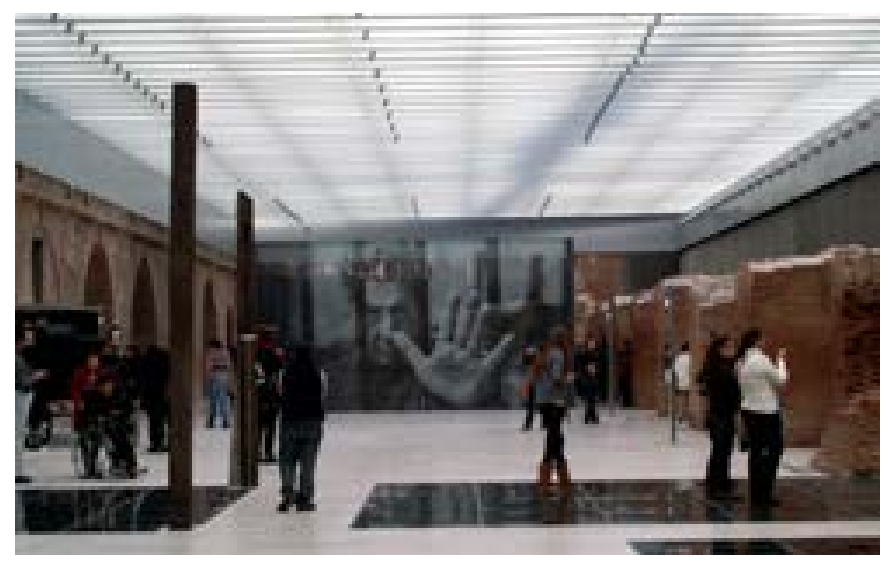

Museo Casa Rosada. Al fondo de la ex Aduana de Taylor, imagen de Siqueiros que ilustra la sala donde se encuentra su mural | foto Facu Gelves

una sociedad para juntar fondos, poder comprar la mansión y recuperar la obra. Su intensión era lograr un beneficio económico de la exposición de Ejercicio Plástico en el exterior. Por cuestiones legales no puede adquirir la residencia, por lo que obtiene el predio y en 1990 hace extraer el mural del sótano, a partir de un enorme trabajo de ingeniería.

Sin embargo, por problemas financieros y judiciales, la pieza no puede ser llevada al exterior y permanece dividia en seis partes en cuatro contenedores en la localidad de San Justo.

Es recién en el año 2003 cuando se logra declarar al mural como bien de interés histórico-artístico nacional a través de Néstor Kirchner, por entonces presidente. Luego en 2007 Cristina Fernández de Kirchner, en aquel tiempo senadora, se compromete en un viaje a México a recuperar y restaurar la obra. Así es que poco después se conforma legalmente la Comisión de recuperación del mural Ejercicio Plástico del artista David Alfaro Siqueiros. Más tarde en 2008, con Cristina Fernández como jefa de Estado, los contenedores son retirados del depósito en que habían permanecido casi veinte años y trasladados a plaza Colón, Capital Federal; para un tiempo después extraerse las piezas y ser ubicadas en un tinglado confeccionado a los efectos de ser analizadas y reparadas. Finalmente en 2010 se expone el mural en la restau-

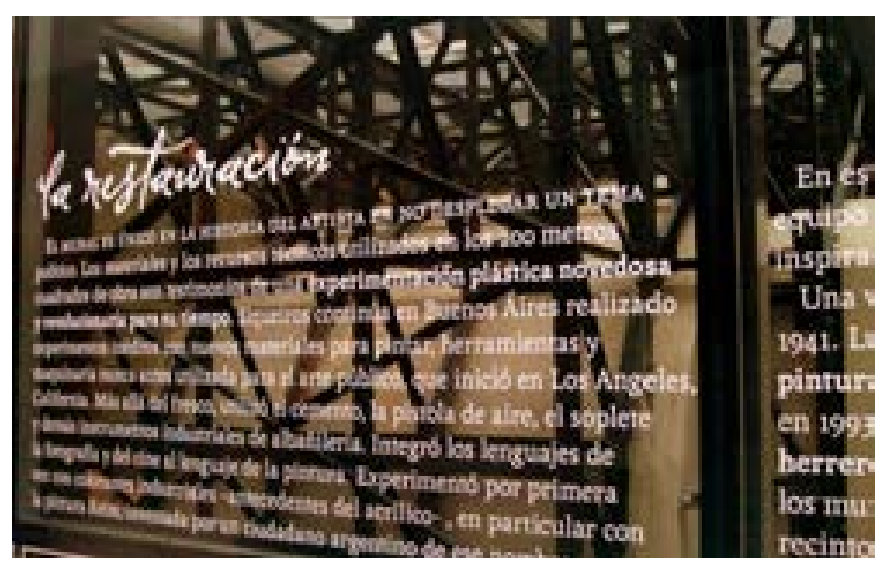

Explicación del proceso de restauracón del mural | foto Facu Gelves

rada ex Aduana de Taylor con motivo de conmemorarse el Bicentenario de Argentina y México, en un museo que recibía su denominación a partir de este hecho.

No es casual, quizás, que Lorena Muñoz (2006) haya tenido en cuenta al componer el juego de palabras que forman el título de su audiovisual documental Los próximos pasados -basado en la historia detrás del mural del Equipo Poligráfico-, las frases citadas en el folleto de Ejercicio Plástico (SIQUEIROS; SPILIMBERGO; LÁZARO; CASTAGNINO; BERNI, 1933: pp. 5-6) acerca de la proyección social de la obra: "...es una APORTACIÓN inicial a la forma revolucionaria, a la técnica correspondiente, de la plástica revolucionaria del presente sangriento y del próximo-futuro victorioso..." y clarifica que su contribución revolucionaria se fundamenta porque: "...todas las experiencias que contiene, en mayor o menor escala, son elementos que ineludiblemente deberán concurrir en la construcción de la plástica pictórica monumental revolucionaria, descubierta, bajo el sol, para las grandes masas, en el próximo futuro y a la realización imperiosa de la plástica multiejemplar simultánea, activa, del presente período de semiilegalidad [sic] e ilegalidad para el proletario revolucionario".

Casi como una visión, el momento actual en que el mural se encuentra emplazado en la ex Aduana de Taylor, y formando parte del Museo Casa Rosada, en un recinto 
a debate Visiones patrimoniales para definir el objeto del siglo

| coordinan José Ramón Moreno Pérez, Marta García de Casasola Gómez

especialmente diseñado para poder ser albergado y exhibido, lo convierte en una pieza de disfrute público en un museo de entrada gratuita; dejando atrás la obra de acceso privado.

Aquello que explicaba Kevin Lynch respecto a "Los límites del futuro" (1975: pp. 108-109) puede aplicarse a las interpretaciones e intervenciones efectuadas en relación al patrimonio cultural: “...deberíamos incrementar el alcance del futuro imaginado, así como el del pasado imaginado, pero únicamente en la medida en que sea coherente con nuestro poder real para recordar, predecir y controlar, es decir, mientras seamos capaces de vivir abiertos en el presente y mientras podamos mantener la coherencia intelectual y emocional de toda nuestra imagen del tiempo".

El patrimonio, como construcción humana situada dentro la historia, siempre será apenas un indicio, posicionado en el "hoy", sobre el pasado y el futuro. Y está bien que así sea.

\section{BIBLIOGRAFÍA}

- DECRETO NACIONAL 1.382/2007, de 9 de octubre, por el que se crea la "Comisión de Recuperación del mural Ejercicio Plástico del artista David Alfaro Siqueiros" cuyo objetivo es la restauración e instalación de la obra a los fines de su exhibición al público y se acuerda su publicación. Boletín Oficial de la República Argentina, de 11 de octubre de 2007 <http:// www.saij.gob.ar/legislacion/decreto-nacional-1382-2007creacion comision recuperacion mural.htm\%3Bjsessionid= n7rxpbluh0223cdblf|n9c6z?0\&bsrc=ci> [Consulta: 31/01/2017]

- LYNCH, K. (1975) ¿De qué tiempo es este lugar? (Trad. Justo G. Beramendi. 2. ${ }^{a}$ ed.). Barcelona: Gustavo Gili, 1975. $285 \mathrm{p}$.

- MUÑOZ, L. (2006) Los próximos pasados [audiovisual documental]. Argentina: Habitación 15-20 Producciones y Productora asociada Liebre Amotinada Ideas, 2006

- REAL ACADEMIA ESPAÑOLA (2017) Indicio. Diccionario de la lengua española [en linea] Madrid, 2017<http://dle.rae. es/?id=LOBECME> [Consulta: 31/01/2017]

- SCHÁVELzoN, D. (ed.) (2010) El mural de Siqueiros en
Argentina: la historia de Ejercicio Plástico. Buenos Aires: Daniel Schávelzon, 2010428 p. <http://www. danielschavelzon. com.ar/ebooks/Mural_Siqueiros_en_Argentina.pdf> [Consulta: 31/01/2017]

- SIQUEIROS, D. A.; SPILIMBERGO, L. E.; LAZARO, E.; CASTAGNINO, J. C.; BERNI, A. (1933) Ejercicio Plástico. Buenos Aires, diciembre 1933. 7 p. <http://www. danielschavelzon.com.ar/ebooks/Mural_Siqueiros.pdf> [Consulta: 31/01/2017]

- VIRNO, P. (2003) El recuerdo del presente. Ensayo sobre el tiempo histórico. Trad. Eduardo Sadier. Buenos Aires: Paidós, 2003. 202 p. 